\title{
Capturing Co-evolutionary Information Systems Alignment: Conceptualization and Scale Development
}

\author{
Pien Walraven \\ Open University of the Netherlands \\ pien.walraven@ou.nl
}

\author{
Rogier van de Wetering \\ Open University of the Netherlands \\ rogier.vandewetering@,ou.nl
}

\author{
Marjolein Caniëls \\ Open University of the Netherlands \\ marjolein.caniels@ou.nl
}

\author{
Johan Versendaal \\ Open University of the Netherlands, \\ Utrecht University of Applied Sciences \\ johan.versendaal@ou.nl
}

\begin{abstract}
Co-evolutionary approaches to business-IT alignment, such as Co-evolutionary information systems alignment (COISA), have gained attention from scholars and practitioners over the last decade. COISA is an organizational capability defined as continuously exercised alignment competencies, characterized by co-evolutionary interactions between heterogeneous IS stakeholders, in pursuit of a common interpretation and implementation of what it means to apply IT in an appropriate and timely way. In spite of some conceptual and empirical work on COISA, a validated operationalization for empirical measurements for science and practice is not available in the extant literature. We developed a measurement scale through acknowledged procedures, entailing a multivariate structural model consisting of specific facilitators leading to effective alignment competencies. To the best of our knowledge, we are the first to propose such a scale.
\end{abstract}

\section{Introduction}

Business-IT alignment, or "applying IT in an appropriate and timely way, in line with business strategies, goals and needs" has been investigated for decades, using both qualitative and quantitative approaches [1], [2]. Moreover, new digital technologies such as blockchain and artificial intelligence, and the growing attention for social and ethical aspects of technology have a major impact on organizations [3]. Furthermore, as organizations become more and more intertwined with their environment and with each other, more and more stakeholders are involved in IS initiatives, making the quest for alignment even more challenging, but nonetheless ever so crucial [4]-[7].

Broadly speaking, traditional alignment research consists of two important schools of thought [1]. The

\author{
Open University of the Netherlands \\ remko.helms@,ou.nl
}

Remko Helms

first one alignment as a state that organizations should strive to obtain (e.g., typology-based alignment assessments such as the one by Sabherwal and Chan [8]), while the second views alignment as a process that needs continuous efforts to be maintained (e.g., the Strategic Alignment Model by Henderson and Venkatraman [9]). A common denominator of these approaches is the focus on the strategic level of alignment and, more implicitly, that the "business" is a homogeneous whole with which IT can be aligned [1]. However, the interwinement of contemporary organizations and increasingly turbulent environments cause different or even contradictory views to emerge on what it means to apply IT appropriately [6], [7]. Therefore, these approaches appear insufficient to effectively tackle the alignment problem.

To address these challenges, scholars have recently turned to co-evolutionary approaches to alignment [5], such as the complex adaptive systems (CAS) theory-based concept of Co-evolutionary Information Systems Alignment (COISA) [10], [11]. COISA applies CAS characteristics to the whole of interacting IS stakeholders, pursuing to reach and maintain a common interpretation and implementation of what it means to apply IT in an appropriate and timely way.

The CAS perspective fits the presumed diversity of mutually interdependent parts of organizational components and the multidirectional interactions among the many stakeholders across the organization [12]. Various scholars argue that this perspective is useful for organizations operating in turbulent environments [12]-[14]. This particular argument stems from the principle of requisite complexity [4], entailing that CAS are on the edge of chaos, demonstrating just enough complexity to effectively respond to environmental turbulence without collapsing into chaos [15]. Several scholars that study alignment from co-evolutionary perspectives have embraced this principle in conceptual papers [4], [16]. Other studies demonstrate initial empirical 
evidence for these ideas in qualitative works [17], [18]. However, no large-scale quantitative empirical studies have been undertaken to further strengthen the claim that organizations whose alignment-related stakeholder interactions reflect CAS characteristics are better prepared for complex conditions. Nor, as an implication, have COISA-based instruments for practitioners been developed to steer applying IT in turbulent environments.

In this current paper, we contribute to closing this gap by executing an initial iteration in developing a validated operationalization for COISA. This instrument can be used for quantitative studies in pursuit of further evidence for CAS-based conceptualizations. Furthermore, practitioners facing turbulent environments with many stakeholders can use the instrument as a checklist to identify improvement areas in pursuit of a more effective alignment capability. Summarizing, our research question is as follows:

RQ: "How can Co-evolutionary Information Systems Alignment be operationalized for the purposes of quantitative studies and practical measurements?

\section{Theoretical foundation}

COISA takes a CAS perspective of organizations. Early works on this concept emphasize that alignment is an emergent phenomenon resulting from co-evolutionary interactions on multiple levels of the organization, i.e., strategic, operational, and individual [4], [16]. This strand of research defines the concept in terms of "[...] the series of coevolutionary moves that make IS aligned over time" [4, p. 288]. More recently, scholars have built a more specific conceptualization upon this foundational work, approaching alignment from the perspective of continuously exercised IS stakeholder interactions within and between co-evolutionary alignment processes. These alignment processes entail the processes where co-evolutionary interactions between IS stakeholders take place, in pursuit of a common interpretation and implementation of what it means to apply IT in an appropriate and timely way, i.e., alignment [6], [7] and reflect the multi-level nature of COISA [4], [5]. Alignment processes can be identified on both operational and strategic levels, as well as between operational and strategic levels and include among others Strategy formulation, Enterprise Architecture Management, and IT implementation [4], [11].

The manifestation of co-evolutionary interactions between IS stakeholders within the aforementioned alignment processes on its own is not sufficient for an organization's alignment processes to effectively maintain a certain level of alignment, as shown in several works on this topic [4], [7], [17], [19]. Specifically, certain facilitators are necessary to ensure stakeholders effectively interact in their pursuit of alignment, in other words, to ensure stakeholders indeed continuously maintain a common interpretation and implementation of what it means to apply IT in an appropriate and timely way. Existing insights on this topic stem from traditional alignment studies, from studies that take co-evolutionary viewpoints on alignment and from studies that focus on efficacious dynamics in complex organizations from a general perspective [7]. Based on these insights, four particular categories of these facilitators in practice can be distinguished [7]. These categories include (I) Stakeholder involvement (who to involve to interact toward alignment effectively?), (II) Interconnections (how to make these interactions toward alignment possible?), (III) Alignment motivation (why should stakeholders bother to contribute to these alignment interactions?) and (IV) Alignment decisions (which decisions within alignment processes help future alignment interactions to be more effective?).

All in all, COISA is an integrative framework consisting of several perspectives, making it challenging to capture its meaning in a single conceptual model. To take on this challenge, we base our next steps on the recommendations as outlined in [20]. These authors recommend ten specific steps for the development of scales intended for quantitative studies. In this current paper, we do an initial iteration and address the first three steps of this approach, including Conceptualization, Development of Measures, and Model Specification. In the following section, we explain each of these steps in further detail.

\section{Conceptualization}

In this first step toward operationalization, we aim to extensively describe the conceptual model of COISA and provide clear definitions of its underlying dimensions [20]. As discussed in the theoretical framework, in earlier studies, COISA has been conceptualized in terms of continuously exercised alignment processes, characterized by coevolutionary interactions between IS stakeholders within and between those alignment processes, enabled by certain facilitators. Some later empirical works on COISA clarify which facilitators are necessary to ensure efficacious co-evolutionary interactions between IS stakeholders in these 
processes, i.e., co-evolutionary interactions that move toward improved alignment among IS stakeholders and not away from it [7], [17], [19].

We undertook two particular steps to deduce a conceptual model suitable for scale development, while staying as true to the original COISA works as possible. First, we defined three different alignment competencies based on the multi-leveled alignment processes we identified in the literature. These alignment competencies include the strategic alignment competency, the orchestrational alignment competency, and the operational alignment competency. These alignment competencies will be explained in more detail later in this section. Second, we synthesized among the facilitators of efficacious alignment interactions to ensure that the core facilitators are included in our final instrument. We finally included two facilitators, i.e. (I) Alignment Motivation and (II) Interconnections between Heterogeneous IS stakeholders.

The resulting conceptualization is compact enough to be suitable for operationalization in survey scales while still theoretically coherent with the original foundations of COISA. We will now further elaborate on this conceptualization process.

\subsection{Alignment processes as the foundations of alignment competencies}

We conceptualize the multi-level co-evolutionary alignment processes in terms of three different alignment competencies. In doing so, we underline that the key focus of COISA consists of the continuous execution of these processes, in line with the internal and external complexity faced by organizations. This insight implies that the alignment processes in themselves cover the intention of the framework only in part. Namely, they reflect where co-evolutionary alignment interactions take place, but not necessarily the continuous execution of the processes themselves and their evolution toward an improved level of alignment among IS stakeholders.

To address this crucial issue, we turn to the concept of organizational competencies as described in [21], who explain based on earlier literature: "[...] competency refers to "a firms capacity to deploy resources, usually in combination, using organizational processes, to effect a desired end" [...] and thus represent "..a bundle of skills and technologies rather than a single, discrete skill or technology" [21, p. 175]. This definition underlines that organizational processes (such as alignment processes) play a vital role in organizational competencies. However, the main focus of organizational competencies is much more on putting organizational resources to use within these processes, as is the case with the intentions of the original COISA model. In other words, we argue that COISA consists of three alignment competencies, manifesting as continuously executed alignment processes, in line with internal and external complexity faced by organizations.

\subsection{COISA as an organizational capability}

Building on the above-described definition of organizational competencies, Peppard and Ward [21] continue their argument toward the concept of organizational capabilities, which they define as "[...] the strategic application of competencies [...], i.e., their use and deployment to accomplish given organizational goals" [21, p. 175]. In the same line of thought, we argue that COISA as a whole, i.e., the combination of all three alignment competencies, efficaciously executed thanks to the presence of needed facilitators that enable efficacious alignment interactions between IS stakeholders, can be seen as an organizational capability. Namely, current insights on COISA suggest that strategic value can only be maintained if all alignment competencies are executed in parallel, given the presence of certain facilitators to ensure efficacious stakeholder interactions toward alignment [4], [17], [19].

In our synthesis of existing insights on facilitators of efficacious COISA interactions, we included facilitators that entail conceptual measures of the coevolutionary alignment interactions between IS stakeholders themselves, including (I) Interconnections between heterogeneous IS stakeholders and (II) alignment motivation. Alignment competencies are expected to be stimulated by these facilitators, and the combination of alignment competencies and their facilitators cover the concept of COISA, as visualized in figure 1. The facilitator "interconnections between heterogeneous IS stakeholders" synthesizes the earlier mentioned categories of stakeholder involvement and interconnections, while the facilitator alignment motivation is directly based on earlier work [7]. We decided to leave out the earlier-mentioned facilitator category "alignment decisions" in our operationalization, because the specific decisions improving future alignment interactions are very much context-dependent and do not directly give insight in the alignment interactions themselves [4], [7], in line with the earlier-described criterion. Therefore, this specific category is not expected to be a reliable indicator to include in a generalizable operationalization of COISA. 


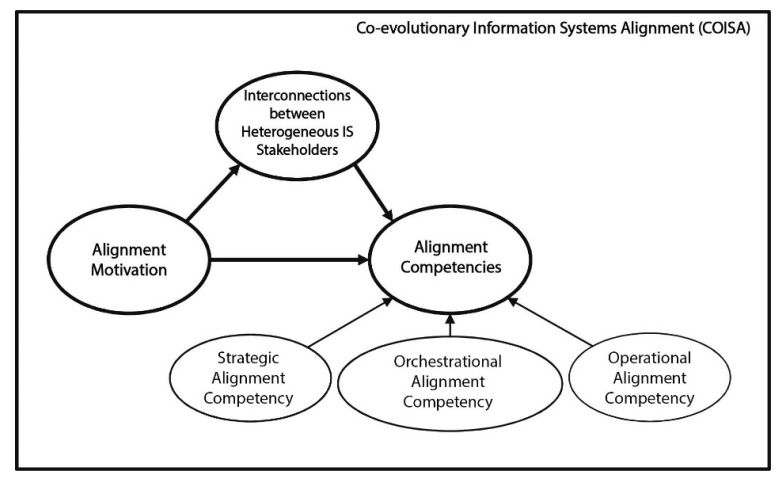

Figure 1. Conceptual model of COISA

The inclusion of the strategic, operational and orchestrational competencies specifically, are based on the results of an earlier structured literature review (SLR). This SLR focused on the specific areas where co-evolutionary interactions manifest in existing studies, leading to the earlier mentioned set of five alignment processes including strategy formulation, strategy implementation, enterprise architecture management, IT implementation and IT usage [11].

We will now elaborate further on the specific operationalizations of each of the individual alignment competencies and the two facilitators that together comprise the COISA capability.

\subsubsection{Strategic alignment competency (STR)}

The first alignment competency entails the strategic alignment competency (STR). This competency consists of the continuous execution of strategic alignment processes including strategy formulation and strategy implementation, where continuous is defined as the degree to which the execution of these processes is in line with the frequencies of internal and external changes faced by the organization at hand. Therefore, we define this competency as follows, coherent with the definitions of these specific alignment processes and continuous co-evolutionary interactions within and between those processes [6], [7], [11]:

An organization's ability to formulate strategic goals, and articulate strategic plans and structures to implement these goals in relation to IS, while monitoring relevance and topicality of these plans, goals, and structures, in line with frequencies of internal and external changes.

\subsubsection{Orchestrational alignment competency (ORCH)}

The orchestrational alignment competency (ORCH) considers co-evolutionary interactions between IS stakeholders in alignment processes bridging operational and strategic levels, essentially referring to the maintenance of a coherent Enterprise Architecture, i.e., coherence between goals, processes, information systems, data, infrastructure, roles, and functions [22]. In doing so, it considers adequate coherence between decisions in strategic and operational alignment competencies, thus orchestrating the COISA capability as a whole [6], [7], [11]. We define the orchestrational alignment competency as follows:

An organization's ability to maintain the coherence of their architecture, through architectural practices such as the definition and application of architectural principles and standards, while monitoring relevance and topicality of these architectural practices, in line with frequencies of strategic and operational changes.

\subsubsection{Operational alignment competency (OP)}

The operational alignment competency (OP) finds its roots in the co-evolutionary interactions between IS stakeholders within and between operational alignment processes such as IT implementation and IT usage. We define this competency as follows [6], [7], [11]:

An organization's ability to collaboratively use IT solutions effectively in daily operations, and to implement and optimize IT solutions in operational settings in line with end-users' needs, while monitoring and leveraging improvement possibilities during IT usage, implementions, and operations.

\subsubsection{Interconnections between heterogeneous IS stakeholders (INT)}

The facilitator of interconnections between heterogeneous IS stakeholders is based on earlier empirical work on facilitators of efficacious coevolutionary alignment interactions [17], [19]. This facilitator entails providing the means to make coevolutionary alignment interactions possible between heterogeneous stakeholders. To do this, as pointed out in [7], IS stakeholders need to have both formal and informal interconnections, as well as supporting platforms to make involvement and co-evolutionary dialogue possible. Summarizing, we define the facilitator of interconnections between heterogeneous IS stakeholders as follows:

The degree to which heterogeneous IS stakeholders have means to engage in coevolutionary alignment interactions within and between alignment processes through formal governance structures, informal networks, and supporting platforms. 


\subsubsection{Alignment motivation (MOT)}

Alignment motivation ensures that IS stakeholders have a reason to engage in coevolutionary alignment interactions. This motivation may be intrinsic, i.e., because IS stakeholders find alignment interactions intrinsically important to engage in. However, these motivations may also be extrinsic, e.g., triggered by legal obligations [7], emerging misalignments [17], or executive management that actively advocates for the importance of leveraging IT [17]. Furthermore, if alignment motivation is present, we expect interconnections among heterogeneous IS stakeholders to also improve because people have actual reasons to develop and maintain these interconnections, as visualized in figure 1 . Based on the above, our definition of alignment motivation is as follows:

The degree to which IS stakeholders are motivated to actively engage in co-evolutionary (twoway) alignment interactions within and between alignment competencies (e.g., through intrinsic motivation, deadlines, legislations, support by Executive Management, being held responsible).

\section{Development of measures}

The second phase of operationalization entails the development of measures. This phase consists of two steps, namely the generation of items to represent the construct and its dimensions, and assessing content validity of those items [20]. To execute this phase, we first looked into existing measures of related concepts that were used in high-quality, peerreviewed journals in the field of IS. We did so by searching the AIS library using key words based on the steps taken as part of the conceptualization phase. To check for this quality criterion, we only evaluated scales in articles published in the basket of eight IS Journals, indicated by the Association for Information Systems [23]. Secondly, we created items ourselves based on key insights of qualitative results on COISA. Our initial item pool consisted of 24 items, as summarized in Table 1.

To assess the content validity of this initial item pool and to improve the items accordingly, we undertook a three-step approach, as visualized in figure 2. The first step consisted of a card sort session among four graduate students in the field of Business Process Management and IT, writing their Master thesis on COISA. Card sort sessions are considered to be an established technique used in instrument development [24], [25]. The second step involved an online survey among IS experts (BSc. degree or above in information science, information systems or a related field), based on [26] and the third and final iteration involved a second card sort session, with two Ph.D. candidates doing alignment-related research, i.e. in the field of Enterprise Architecture and Dynamic Capabilities, and two practitioners active in a large Dutch public organization and familiar with the challenges of alignment (i.e., one business analyst and one enterprise architect). We will now elaborate on each of these steps.

Table 1. Initial items to measure COISA

\begin{tabular}{|c|c|c|}
\hline Construct & \#items & Source \\
\hline STR & 4 & $\begin{array}{c}\text { Self-generated based on [6], } \\
\text { adapted from [27] }\end{array}$ \\
\hline ORCH & 4 & Adapted from [22] and [27] \\
\hline OP & 4 & Adapted from [27]-[29] \\
\hline INT & 6 & Self-generated based on [6] and [7] \\
\hline MOT & 6 & $\begin{array}{c}\text { Self-generated based on [6], [7], } \\
{[17],[30]-[32], \text { adapted from [27] }}\end{array}$ \\
\hline
\end{tabular}

\subsection{Card sort session 1}

The goal of the first card sort session was twofold: Firstly, we intended to check whether respondents placed the items in the hypothesized category, giving some first indications of content validity (i.e., do these items measure what they intend to measure?).

Secondly, we aimed to evaluate the formulation and completeness of the items by carrying out an indepth discussion after the sorting was finished. The set-up of this first card sort session was as follows: The session started with a video recorded miniinstruction on the conceptual basis of COISA, after which the students were asked to individually categorize each of the 24 items under the COISA dimension they deemed the best fitting.

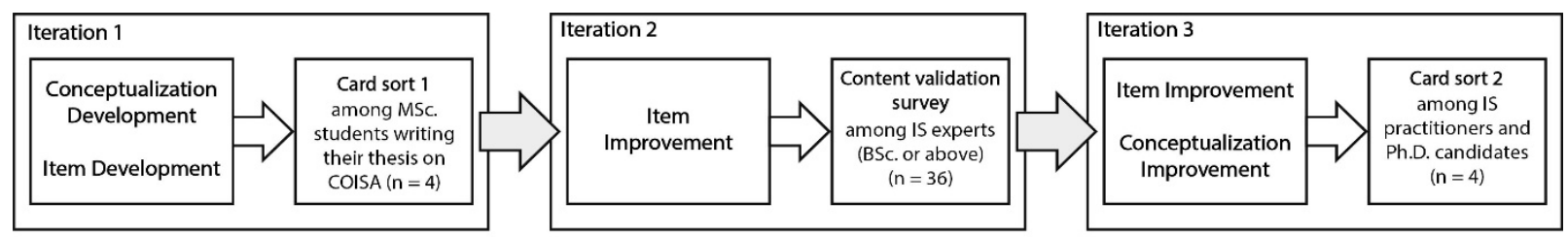

Figure 2. Iterations undertaken in the "Development of measurements" phase 
Following, we discussed their sortings and argumentations on why they chose specific categories in specific cases, and asked for additional feedback on the item formulation, comprehensibility, and underlying concepts. This discussion was recorded and transcribed to enable the processing of qualitative feedback on specific items. To analyze the results of this card sort session, we first assessed overall hit ratios, i.e., the number of times that participants placed an item in the intended categories. Furthermore, we assessed Fleiss' Kappa, which is deemed an appropriate instrument to assess interrater agreement among more than two raters [33]. The results of this first card sort session are summarized in table $2(\mathrm{Ohr}=47,9$, Avg kappa $=0,12)$.

A high overall hit rate is necessary to ensure adequate content validity of an item set, as well as an average kappa of at least 0,65 [25]. These criteria were insufficiently met in this first card sort session. However, the qualitative suggestions in the constructive discussion afterwards lead to several changes, including changes in item formulation, and dropping particular items. With the improved set of items, we started the second iteration in our development of measures, i.e., the content validation survey.

Table 2. Results of card sort session 1

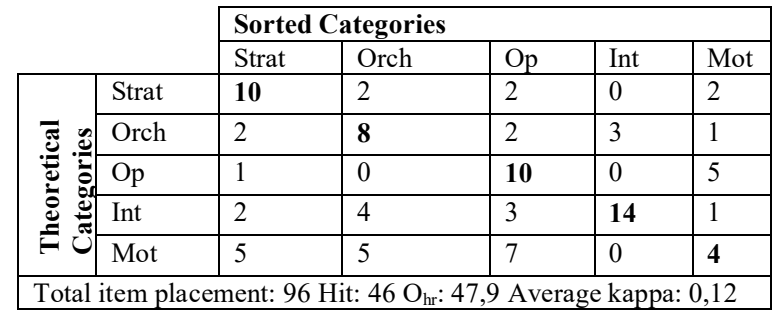

\subsection{Content validation survey}

The second step we underook to assess and improve content validity entailed an online survey among IS experts (i.e., students, academics and practitioners with a completed BSc. Degree or above in information systems, information science or a related field). The goal of this particular survey was to evaluate whether the improvements applied based on the first card sort session were effective enough to argue that the renewed item set has an adequate level of content validity. In this survey, participants were first asked to indicate their level and field of education to enable us to make the first selection in usable replies. Following, participants were asked to view the same video recorded mini-instruction as was used in the first card sorting session.

To assess whether respondents had a good understanding of the concept of COISA and were thus suited for this study, we asked respondents to indicate their understanding of the video on a scale from 1 ("I have watched the mini instruction, but I did not understand the content at all") to 5 ("I have watched the mini instruction and the content is completely clear to me"). Respondents were then asked to assess the degree to which they found each item representative for each of the five COISA dimensions (strategic alignment competency, orchestrational alignment competency, operational alignment competency, interconnections between heterogeneous employees and alignment motivation). The content validity assessment by respondents was done using a 5-point Likert scale ranging from "not at all representative (1) to "very representative" (5).

This approach to content validity assessment is based on the recommendations as outlined in [26]. These authors utilized a comparable approach for instrument development, except we opted for an online set-up. To recruit participants, we applied a convenience sampling approach and asked our direct and indirect colleagues, and spread requests via Twitter and LinkedIn asking for academics with a background in information science, information systems, or a related field to contact us for this particular study.

Out of the 52 complete responses, we were able to take into account 36 , which met all of our quality criteria, i.e., respondents had at least a completed BSc. degree in Information Systems, Information Science or a related field, and who indicated that they understood the mini-instruction well (score 4 on the 5-pt Likert scale) or that the content of the miniinstruction was completely clear to them (score 5).

Unfortunately, the number of respondents is too low to perform factor analyses, as was recommended for data analysis in the original work that formed the basis of this methodology [26]. However, we still deemed the input of 36 IS experts highly valuable in our content validation improvement process and thus opted for a different analysis approach to leverage these inputs as much as possible. Specifically, we started from the assumption that items that reflect their intended category well, i.e., items that have adequate content validity, should have high mean scores on their intended category. We thus calculated for each item the mean value for each category and looked at the standard deviation. We considered items that met the following criteria to be sufficiently content valid: (I) Mean value of the intended category is higher than 4.0; (II) Mean value on other categories do not exceed the mean value of the intended category; (III) Stdev is not higher than 1.0. As a result, three items remained for SAC, one for OPAC, two for ORAC, four for HIS and one for AM. 
Based on these results, we took several steps in preparation for the third iteration of measurement development: We first critically reviewed the items with insufficient scores and compared them to qualitative feedback we received as a reply to this survey. Several items were reformulated or entirely dropped based on this analysis. Looking further into the data, we noticed that a frequently occurring problem was that some items had relatively high mean scores $(>3)$ spread across different categories. We therefore concluded that our initial definitions of the COISA dimensions were insufficiently distinguishable from each other. We thus did another conceptualization iteration through extensive discussions among our team, which lead to the definitions found in this current paper. Lastly, we formulated several new items to ensure that each dimension has four representing items.

\subsection{Card sort session 2}

The final iteration of our content validity phase consisted of a second card sort session, this time with two Ph.D. candidates in the field of Information Systems and two practitioners, i.e., one enterprise architect and one business analyst. In this session, we did not make use of the video instruction anymore, as one of the measures we took based on the second iteration in this process entailed improvement in terms of conceptualizations and definitions, leaving the video instruction outdated. Instead, one of the researchers provided a mini-lecture at the beginning of the card sort session, along with a document where definitions of COISA and its subdimensions could be found. The rest of the set-up of this card sort session was the same as our first card sort session: respondents were asked to individually categorize each of the 20 items under the category that they found the best fitting. Again, we performed analyses to retrieve the overall hit rate and calculated Fleiss' Kappa to assess inter-rater reliability [33]. The results of this second card sort session are summarized in table $3(\mathrm{Ohr}=93,8$, Avg Kappa $=0.84)$.

This leads to a total of 20 content validated items, i.e., four items for each of the underlying dimensions of COISA. The final complete operationalization is included in the appendix of this article.

Table 3. Results of card sort session 2

\begin{tabular}{|c|c|c|c|c|c|c|}
\hline & \multicolumn{5}{|c|}{ Sorted Categories } \\
\hline & & Strat & Orch & Op & Int & Mot \\
\hline \multirow{5}{*}{ 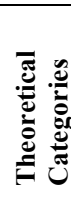 } & Strat & 15 & 1 & 0 & 0 & 0 \\
\hline & Orch & 1 & 15 & 0 & 0 & 0 \\
\hline & Op & 0 & 1 & 15 & 0 & 0 \\
\hline & Int & 0 & 0 & 0 & 15 & 1 \\
\hline & Mot & 0 & 1 & 0 & 0 & 15 \\
\hline
\end{tabular}

\section{Model specification}

The phase of model specification considers the formal specification of the nature of the relationships between the established indicators and between the different sub-dimensions of COISA [20]. COISA consists of several different perspectives that form an integrative whole and thus cannot be captured in a single dimension or even a single concept. In fact, following our conceptualization, two crucial parts of a slightly different nature can be distinguished: firstly, the concept of alignment competencies. This first part is conceptualized as a multiplicative aggregate concept based on the parallel manifestation of the strategic alignment competency, the orchestrational alignment competency, and the operational alignment competency. This concept is modeled as a first-order reflective, second-order formative concept because the three different alignment competencies are not interchangeable, and the meaning of the concept is only adequately reflected when all three subdimensions are present [34]. Hence, this first part can be classified as a reflective-formative type II model [35], [36], which has been applied to various related IS construct conceptualizations and validations [24], [37], [38]. Items representing a single alignment competency (e.g., Str1-Str4) are interchangeable and thus are reflectively related to the first-order alignment competencies

The second part of the model consists of the two alignment facilitators, i.e., interconnections between heterogeneous IS stakeholders and alignment motivation. Since these facilitators can be seen as boundary conditions for the alignment competencies to reflect CAS characteristics, we argue that they should be included in multivariate structural models of future quantitative studies as independent variables positively influencing alignment competencies.

Summarizing, the conceptualization of COISA as a whole is in itself part of a multivariate structural model, as visualized in figure 3 . This approach is in

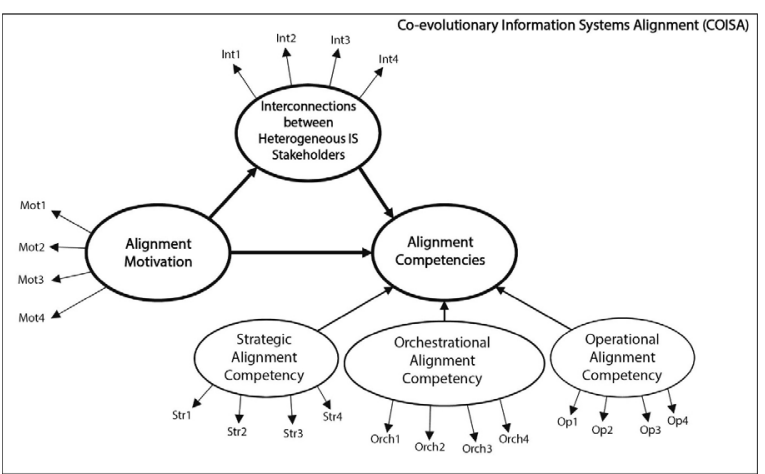

Figure 3. COISA measurement model 
line with recommendations in [39], who argue that this type of conceptualization is best suitable for measuring concepts where "[...] a general idea exists behind the set of dimensions" (in this case, the ideas behind complex adaptive systems and the related principle of requisite complexity) and where "dimensions are distinct but don't represent a single theoretical concept" (since the dimensions considering alignment competencies are clearly of a different nature than the dimensions considering the facilitators of efficacious alignment interactions).

Another essential element of model specification entails the formulation of scale labels. For the independent concepts, interconnections between heterogeneous IS stakeholders and alignment motivation, we opted for an often-applied 7-point Likert scale, ranging from "Strongly disagree"(1) to "Strongly agree" (7), as is visible in the appendix. In the case of the alignment competencies, we opted for a more context-aware labeling of scale, where scores are dependent on frequencies of change faced by the organization, bot externally and internally, and both on the operational and strategic level. These contextaware scales are more in line with our core definitions of alignment competencies, and are also better suited for complex organizations, that are characterized by context-dependent issues [4]. The specific labeling of the scales for each alignment competency is shown in the appendix.

\section{Discussion, conclusion, future research}

In this paper, we aimed to develop an operationalization of COISA for quantitative and practical measurements. In doing so, we presented a measurement instrument that is considered to have adequate content validity, based on the recommendations in [20]. This instrument provides IS researchers with the opportunity to use quantitative approaches in studying COISA. Specifically, it provides the first step to larger-scale empirical studies looking into the premise that organizations facing complex conditions are better able to shape organizational capabilities when they leverage CAS principles. Moreover, practitioners can use the developed conceptualization and corresponding operationalization to measure their own COISA capability and identify specific improvement areas to further develop this capability.

Although the currently developed measurement instrument provides a valuable step towards more empirical research on COISA, our study is subject to several limitations. Firstly, the focus of this current paper and the steps we carried out were focused mainly on establishing content validity. As described, this considers the first three steps as prescribed in [20], including conceptualization, development of measures, and model specification. However, to further strengthen the validation of this measurement instrument, two extra steps are needed. First, data needs to be collected from an initial set of respondents to perform a pre-test to purify and refine the scale. Following, a second dataset should be collected to enable scale validity assessment and cross-validation [20]. Future studies should focus on these steps to address these particular endeavours.

Furthermore, we found that content validation surveys are challenging to be carried out online, since it is difficult to convey the survey's intention via written text only. We suggest future researchers that want to leverage the benefits of a quantitative approach here, to make sure that a clear explanation of the survey's intention is somehow included. This could be done during an in-person lecture, but it could for example also be facilitated by including an explanatory video at the beginning of the survey.

Lastly, it would be valuable to also assess the concept in relation to other, higher-order organizational capabilities, especially for organizations facing complex conditions. In doing so, another fruitful line of thought could involve the use of configurational approaches, to shed more light on the value of CAS-based conceptualizations of alignment in complex situations [5].

\section{References}

[1] Y. E. Chan and B. H. Reich, "IT alignment: what have we learned?," J. Inf. Technol., vol. 22, no. 4, pp. 297-315, 2007.

[2] J. Luftman and R. Kempaiah, "An Update on Business-IT Alignment:" A Line" Has Been Drawn," MIS Q. Exec., vol. 6, no. 3, 2007.

[3] D. Cearly, N. Jones, D. Smith, B. Burke, A. Chandrasekaran, and C. Lu, "Top 10 Strategic Technology Trends for 2020," 2019.

[4] H. Benbya and B. McKelvey, "Using coevolutionary and complexity theories to improve IS alignment: a multi-level approach," J. Inf. Technol., vol. 21, no. 4, pp. 284-298, 2006.

[5] H. Benbya, H. Tanriverdi, and Y. Yoo, "Complexity and information systems research in the emerging digital world," MIS Q., vol. 44, no. 1, pp. 1-17, 2020.

[6] P. Walraven, R. Van De Wetering, J. Versendaal, and M. Caniëls, "Using a Co-evolutionary IS-alignment approach to understand EMR implementations," in ECIS 2019 Proceedings, 2019.

[7] P. Walraven, R. van de Wetering, R. Helms, and M. Caniëls, "Aligning effectively: the case of Electronic Medical Records," in ECIS 2020 Proceedings, 2020.

[8] R. Sabherwal and Y. E. Chan, "Alignment between business and IS strategies: A study of prospectors, 
analyzers, and defenders," Inf. Syst. Res., vol. 12, no. 1, pp. 11-33, 2001.

[9] J. C. Henderson and H. Venkatraman, "Strategic alignment: Leveraging information technology for transforming organizations," IBM Syst. J., vol. 32, no. 1, pp. 472-484, 1993.

[10] H. Benbya and B. McKelvey, "Toward a complexity theory of information systems development," Inf. Technol. People, vol. 19, no. 1, pp. 12-34, 2006.

[11] P. Walraven, R. van de Wetering, R. Helms, J. Versendaal, and M. Caniëls, "Co-evolutionary ISalignment: a complex adaptive systems perspective," in MCIS 2018 Proceedings, 2018.

[12] R. Van de Wetering, "Modeling alignment as a higher order nomological framework," in International Conference on Business Information Systems, 2016, pp. 111-122.

[13] Y. Merali, T. Papadopoulos, and T. Nadkarni, "Information systems strategy: Past, present, future?," J. Strateg. Inf. Syst., vol. 21, no. 2, pp. 125153, 2012.

[14] Y. Merali and B. McKelvey, "Using Complexity Science to effect a paradigm shift in Information Systems for the 21 st century," J. Inf. Technol., vol. 21, no. 4, pp. 211-215, 2006.

[15] J. H. Holland, Hidden order: how adaptation builds complexity. 1995.

[16] P. M. Allen and L. Varga, “A co-Evolutionary Complex Systems Perspective on Information Systems," J. Inf. Technol., vol. 21, no. 4, pp. 229 238, 2006.

[17] F. Amarilli, M. Van Vliet, and B. Van den Hooff, "An explanatory study on the co-evolutionary mechanisms of business IT alignment," in ICIS 2017 Proceedings, 2017.

[18] D. Yim, J. Khuntia, S. Lim, and W. Duan, "To ask or not to ask? An investigation of user engagement and doctor-seeking decision in online health infomediary," in ICIS 2017 Proceedings, 2017.

[19] M. Zhang, H. Chen, and K. Lyytinen, "Principles of Organizational Co-evolution of Business and IT: A Complexity Perspective," in ECIS 2019 Proceedings, 2019.

[20] S. B. MacKenzie, P. M. Podsakoff, and N. P. Podsakoff, "Construct measurement and validation procedures in MIS and behavioral research: Integrating new and existing techniques," MIS Q., vol. 35 , no. 2, pp. 293-334, 2011

[21] J. Peppard and J. Ward, "Beyond strategic information systems: towards an IS capability," $J$. Strateg. Inf. Syst., vol. 13, no. 2, pp. 167-194, 2004.

[22] C. Schmidt and P. Buxmann, "Outcomes and success factors of enterprise IT architecture management: empirical insight from the international financial services industry," Eur. J. Inf. Syst., vol. 20, no. 2, pp. 168-185, 2011.

[23] "Senior Scholars' Basket of Journals." [Online]. Available: https://aisnet.org/general/custom.asp?page=SeniorSc holarBasket. [Accessed: 01-Nov-2019].

[24] P. Mikalef and A. Pateli, "Developing and validating a measurement instrument of IT-enabled dynamic capabilities," in ECIS 2016 Proceedings, 2016.

[25] G. C. Moore and I. Benbasat, "Development of an instrument to measure the perceptions of adopting an information technology innovation," Inf. Syst. Res., vol. 2, no. 3, pp. 192-222, 1991.

[26] C. A. Schriesheim, C. C. Cogliser, T. A. Scandura, M. J. Lankau, and K. J. Powers, "An empirical comparison of approaches for quantitatively assessing the content adequacy of paper-and-pencil measurement instruments," Organ. Res. Methods, vol. 2, no. 2, pp. 140-156, 1999.

[27] G. Kim, B. Shin, K. K. Kim, and H. G. Lee, "IT capabilities, process-oriented dynamic capabilities, and firm financial performance," J. Assoc. Inf. Syst., vol. 12, no. 7, p. 1, 2011.

[28] Y. Wu, B. Choi, X. Guo, and K. T.-T. Chang, "Understanding user adaptation toward a new IT system in organizations: A social network perspective," J. Assoc. Inf. Syst., vol. 18, no. 11, pp. 787-813, 2017.

[29] H. Barki, R. Titah, and C. Boffo, "Information system use-related activity: an expanded behavioral conceptualization of individual-level information system use," Inf. Syst. Res., vol. 18, no. 2, pp. 173192, 2007.

[30] E. McLean and J. Luftman, "Key issues for IT executives," MIS Q. Exec., vol. 3, no. 2, 2004.

[31] J. Luftman, R. Papp, and T. Brier, "Enablers and inhibitors of business-IT alignment," Commun. Assoc. Inf. Syst., vol. 1, no. 1, p. 11, 1999.

[32] M.-S. Pang, G. Lee, and W. H. DeLone, "IT resources, organizational capabilities, and value creation in public-sector organizations: a public-value management perspective," J. Inf. Technol., vol. 29, no. 3, pp. 187-205, 2014.

[33] J. L. Fleiss, "Measuring nominal scale agreement among many raters.," Psychol. Bull., vol. 76, no. 5, p. 378, 1971.

[34] G. Kim, B. Shin, and V. Grover, "Research note: Investigating two contradictory views of formative measurement in information systems research," MIS Q., pp. 345-365, 2010.

[35] J.-M. Becker, K. Klein, and M. Wetzels, "Hierarchical latent variable models in PLS-SEM: guidelines for using reflective-formative type models," Long Range Plann., vol. 45, no. 5-6, pp. 359-394, 2012.

[36] C. B. Jarvis, S. B. MacKenzie, and P. M. Podsakoff, "A critical review of construct indicators and measurement model misspecification in marketing and consumer research," J. Consum. Res., vol. 30, no. 2, pp. 199-218, 2003.

[37] P. A. Pavlou and O. A. El Sawy, "From IT leveraging competence to competitive advantage in turbulent environments: The case of new product development," Inf. Syst. Res., vol. 17, no. 3, pp. 198227, 2006.

[38] R. van de Wetering, "Dynamic Enterprise Architecture Capabilities: Conceptualization and Validation," in International Conference on Business 
Information Systems, 2019, pp. 221-232.

[39] G. L. Polites, N. Roberts, and J. Thatcher, "Conceptualizing models using multidimensional constructs: a review and guidelines for their use," Eur. J. Inf. Syst., vol. 21, no. 1, pp. 22-48, 201

\section{Appendix: final operationalization}

\begin{tabular}{|c|c|c|}
\hline Dimension & Items & \multirow{5}{*}{$\begin{array}{l}\text { Scale } \\
\text { 1. Never } \\
\text { 2. Way too infrequently given internal } \\
\text { and external changes } \\
\text { 3. Too infrequently, given internal and } \\
\text { external changes } \\
\text { 4. Somewhat in line with frequencies } \\
\text { of internal and external changes } \\
\text { 5. Moderately in line with frequencies } \\
\text { of internal and external changes } \\
\text { 6. Mostly in line with frequencies of } \\
\text { internal and external changes } \\
\text { 7. Completely in line with frequencies } \\
\text { of internal and external changes }\end{array}$} \\
\hline \multirow{4}{*}{$\begin{array}{l}\text { Strategic } \\
\text { alignment } \\
\text { competency }\end{array}$} & $\begin{array}{l}\text { STR1. Our organization periodically performs strategic IT planning } \\
\text { processes (e.g., prioritizing IT projects)" (Adapted from [27], refined } \\
\text { during development of measures (DOM) iteration) }\end{array}$ & \\
\hline & $\begin{array}{l}\text { STR2. Our organization frequently adjusts strategic goals to better adapt } \\
\text { to changing conditions (Adapted from [27], refined during DOM } \\
\text { iteration) }\end{array}$ & \\
\hline & $\begin{array}{l}\text { STR3. Our organization continuously works on creating the right } \\
\text { conditions to enable implementation of strategic goals in relation to IT } \\
\text { (e.g., setting up program structures and creating roadmaps) (Based on [6], } \\
\text { after DOM iteration) }\end{array}$ & \\
\hline & $\begin{array}{l}\text { STR4. When making strategic IT investment decisions, our organization } \\
\text { actively considers strategic goals from different departments, roles and } \\
\text { perspectives (Based on [6], after DOM iteration) }\end{array}$ & \\
\hline \multirow{4}{*}{$\begin{array}{l}\text { Orchestrational } \\
\text { alignment } \\
\text { competency }\end{array}$} & $\begin{array}{l}\text { ORCH1. Our organization continuously works on maintaining } \\
\text { architectural principles and standards to guide systems development and } \\
\text { maintenance projects (Adapted from [22], refined during DOM iteration) }\end{array}$ & \multirow{4}{*}{$\begin{array}{l}\text { 1. Never } \\
\text { 2. Way too infrequently, given } \\
\text { strategic and operational changes } \\
\text { 3. Too infrequently, given strategic and } \\
\text { operational changes } \\
\text { 4. Somewhat in line with frequencies } \\
\text { of strategic and operational changes } \\
\text { 5. Moderately in line with frequencies } \\
\text { of strategic and operational changes } \\
\text { 6. Mostly in line with frequencies of } \\
\text { strategic and operational changes } \\
\text { 7. Completely in line with frequencies } \\
\text { of strategic and operational changes }\end{array}$} \\
\hline & $\begin{array}{l}\text { ORCH2. Our organization continuously works on maintaining overall } \\
\text { coherence between different processes, roles and IT components (Based } \\
\text { on [6], after DOM iteration) }\end{array}$ & \\
\hline & $\begin{array}{l}\text { ORCH3. When making architectural decisions, our organization actively } \\
\text { considers coherence with strategic principles and goals (Based on [6], } \\
\text { after DOM iteration) }\end{array}$ & \\
\hline & $\begin{array}{l}\text { ORCH4. Our organization actively works on ensuring relevance and } \\
\text { topicality of architectural practices, principles and standards and makes } \\
\text { changes accordingly (Based on [6], after DOM iteration) }\end{array}$ & \\
\hline \multirow{4}{*}{$\begin{array}{l}\text { Operational } \\
\text { alignment } \\
\text { competency }\end{array}$} & $\begin{array}{l}\text { OP1. Overall, end users spend efforts in recommending changes to IT in } \\
\text { use to better fit their works (Adapted from [28], [29]) }\end{array}$ & \multirow{4}{*}{$\begin{array}{l}\text { 1. Never } \\
\text { 2. Way too infrequently to leverage } \\
\text { any opportunities for improvement } \\
\text { 3. Too infrequently to leverage many } \\
\text { opportunities for improvement } \\
\text { 4. To the degree that we leverage some } \\
\text { opportunities for improvement } \\
\text { 5. To the degree that we leverage a } \\
\text { moderate amount of opportunities } \\
\text { for improvement } \\
\text { 6. To the degree that we leverage a } \\
\text { considerable amount of } \\
\text { opportunities for improvement } \\
\text { 7. To the degree that we leverage } \\
\text { (almost) all opportunities for } \\
\text { improvement }\end{array}$} \\
\hline & $\begin{array}{l}\text { OP2. Overall, end users spend efforts on changing their tasks so that these } \\
\text { better fit the IT in use (Adapted from [28], [29]) }\end{array}$ & \\
\hline & $\begin{array}{l}\text { OP3. Our organization continuously works on implementing and } \\
\text { improving IT systems in operational settings (Adapted from [27], refined } \\
\text { during DOM iteration) }\end{array}$ & \\
\hline & $\begin{array}{l}\text { OP4. Our organization continuously evaluates implemented IT systems } \\
\text { for alignment with business processes and working routines (Based on } \\
\text { [6], after DOM iteration) }\end{array}$ & \\
\hline \multirow{4}{*}{$\begin{array}{l}\text { Interconnections } \\
\text { between } \\
\text { heterogeneous IS } \\
\text { stakeholders }\end{array}$} & $\begin{array}{l}\text { INT1. Our organization ensures adequate stakeholder participation in IT } \\
\text { development and -improvement efforts (Based on [6], after DOM } \\
\text { iteration) }\end{array}$ & \multirow{4}{*}{$\begin{array}{l}\text { 1. Strongly disagree } \\
\text { 2. Disagree } \\
\text { 3. Somewhat disagree } \\
\text { 4. Neither agree nor disagree } \\
\text { 5. Somewhat agree } \\
\text { 6. Agree } \\
\text { 7. Strongly agree }\end{array}$} \\
\hline & $\begin{array}{l}\text { INT2. In our organization, IS/IT people and line people from various } \\
\text { departments periodically attend cross-functional meetings (Adapted from } \\
\text { [27]) }\end{array}$ & \\
\hline & $\begin{array}{l}\text { INT3. Our organization takes conscious action to improve informal } \\
\text { connections across functions and departments (Based on [6]) }\end{array}$ & \\
\hline & $\begin{array}{l}\text { INT4. We have a dedicated platform where we share information across } \\
\text { functions and departments, related to IT alignment efforts (Based on [6]) }\end{array}$ & \\
\hline \multirow{4}{*}{$\begin{array}{l}\text { Alignment } \\
\text { motivation }\end{array}$} & $\begin{array}{l}\text { MOT1. Our employees are intrinsically motivated to continuously } \\
\text { leverage and improve IT initiatives (Based on [6]) }\end{array}$ & \multirow{4}{*}{$\begin{array}{l}\text { 1. Strongly disagree } \\
\text { 2. Disagree } \\
\text { 3. Somewhat disagree } \\
\text { 4. Neither agree nor disagree } \\
\text { 5. Somewhat agree } \\
\text { 6. Agree } \\
7 \text { Strongly agree }\end{array}$} \\
\hline & $\begin{array}{l}\text { MOT2. Generally, our employees are enthusiastic to contribute to IT } \\
\text { initiatives (Based on [6], after DOM iteration) }\end{array}$ & \\
\hline & $\begin{array}{l}\text { MOT3. Our employees generally feel stimulated to engage in dialogues } \\
\text { related to IT initiatives (Based on [6], after DOM iteration) }\end{array}$ & \\
\hline & $\begin{array}{l}\text { MOT4. Our employees have clear reasons to actively collaborate with } \\
\text { other stakeholders on leveraging and improving IT initiatives (Based on } \\
\text { [6], after DOM iteration) }\end{array}$ & \\
\hline
\end{tabular}

